Article

\title{
Ultrafast All-Optical Signal Modulation Induced by Optical Kerr Effect in a Tellurite Photonic Bandgap Fiber
}

\author{
Tonglei Cheng ${ }^{1}$, Fan Zhang ${ }^{1}$, Shunta Tanaka ${ }^{2}$, Shuguang Li ${ }^{1}$, Xin Yan ${ }^{1}{ }^{(}$, , Xuenan Zhang ${ }^{1, *}$, \\ Takenobu Suzuki ${ }^{2}$ and Yasutake Ohishi ${ }^{2}$ \\ 1 State Key Laboratory of Synthetical Automation for Process Industries, College of Information Science and \\ Engineering, Northeastern University, Shenyang 110819, China; chengtonglei@ise.neu.edu.cn (T.C.); \\ zhangfan88819@hotmail.com (F.Z.); lishuguang@ise.neu.edu.cn (S.L.); yanxin@ise.neu.edu.cn (X.Y.) \\ 2 Research Center for Advanced Photon Technology, Toyota Technological Institute, 2-12-1, Hisakata, \\ Tempaku, Nagoya 468-8511, Japan; shunta.tanaka123@gmail.com (S.T.); takenobu@toyota-ti.ac.jp (T.S.); \\ ohishi@toyota-ti.ac.jp (Y.O.) \\ * Correspondence: zhangxuenan@ise.neu.edu.cn
}

Received: 9 September 2019; Accepted: 28 October 2019; Published: 29 October 2019

\begin{abstract}
Ultrafast all-optical signal modulation induced by optical Kerr effect (OKE) was demonstrated in an all-solid tellurite photonic bandgap fiber (PBGF) which was designed and fabricated based on $\mathrm{TeO}_{2}-\mathrm{Li}_{2} \mathrm{O}-\mathrm{WO}_{3}-\mathrm{MoO}_{3}-\mathrm{Nb}_{2} \mathrm{O}_{5}$ (TLWMN, high-index rods), $\mathrm{TeO}_{2}-\mathrm{ZnO}-\mathrm{Na}_{2} \mathrm{O}-\mathrm{La}_{2} \mathrm{O}_{3}$ (TZNL, background), and $\mathrm{TeO}_{2}-\mathrm{ZnO}-\mathrm{Li}_{2} \mathrm{O}-\mathrm{K}_{2} \mathrm{O}-\mathrm{Al}_{2} \mathrm{O}_{3}-\mathrm{P}_{2} \mathrm{O}_{5}$ (TZLKAP, cladding) glasses. At the input of a control pulse with high intensity, OKE occurred in the tellurite PBGF and the transmission bands of the tellurite PBGF shifted. The signal at $1.57 \mu \mathrm{m}$ transmitting in the fiber core can be ultrafast all-optically modulated by the ultrafast single pulse $(200 \mathrm{~kW}, 200 \mathrm{fs})$ under OKE, where the modulation speed can reach $50 \mathrm{GHz}$, faster than some commercial $\mathrm{LiNbO}_{3}$ modulators. The results in this paper can be applied to multi-monitors, local area network, detectors, multi-sources, etc.
\end{abstract}

Keywords: signal modulation; optical Kerr effect; all-solid tellurite photonic bandgap fiber

\section{Introduction}

Optical Kerr effect (OKE) is a third-order nonlinear phenomenon which refers to a change in the refractive index induced by an applied electric field through a nonlinear polarization [1-5]. In optical fibers, it has already been applied to controlling the phase shift and the dispersion [6-8]. However, because the nonlinear refractive index coefficient of the silica material $\left(2.6 \times 10^{-20} \mathrm{~m}^{2} / \mathrm{W}\right)$ is small, OKE is usually neglected in traditional optical fibers [9]. Recently, tellurite glass has attracted great attention and optical fibers fabricated based on it have been used for nonlinear optics, optical fiber lasers and amplifiers, and optical communication [10-14]. This novel fiber material has many excellent features such as good thermal stability, chemical durability, and wide transmission range in the mid-infrared region [15-18]. Particularly, its refractive index coefficient $\left(5.9 \times 10^{-19} \mathrm{~m}^{2} / \mathrm{W}\right)$ is more than one order of magnitude larger than that of silica [19], which is highly advantageous for obtaining significant OKE.

All-solid photonic bandgap fibers (PBGFs), which are composed of high-index rods periodically embedded in a low index cladding, can give rise to a forbidden frequency band for light propagation [17, 20-22], and have already been applied to tunable bandpass filters and nonlinear optical devices [23-26]. Managing to combine tellurite's material advantage and PBGF's structural features together, our group has successfully produced all-solid tellurite PBGFs and further explored in detail their fabrication procedure, transmission characteristics, and photonic bandgap (PBG) property $[27,28]$. In these novel 
fibers, OKE will become significant when pulses of high intensity transmit in the fiber core, which may possibly induce novel optical phenomena.

In this paper, we demonstrate the ultrafast all-optical signal modulation induced by OKE in an all-solid tellurite PBGF. The fiber was specifically designed, which had a double-cladding structure and possessed thermal compatibility among high-index rods, the background, and the cladding. The signal transmitting in the fiber core can be ultrafast all-optically modulated by the ultrafast single pulse under OKE, and an all-optical switch system can be developed.

\section{Fabrication and Properties of All-Solid Double-Clad Tellurite PBGF}

OKE refers to the phenomenon that the refractive index $(n)$ of the fiber core depends on the intensity of the control pulse transmitting in it, which can be given by $n=n_{0}+n_{2} I_{i n}$. $n_{0}$ is the linear refractive index of the core material, $n_{2}$ is the nonlinear refractive index, and $I_{\text {in }}$ is the intensity of the control pulse. Figure 1a shows the circumstance of a control pulse with intensity $I_{\text {in }}$ transmitting in the core of an all-solid PBGF, in which the refractive index of the background and the high-index rods is $n_{0}$ and $n_{1}$, respectively. Although the control pulse intensity is in Gauss distribution, to facilitate the calculation, we suppose the control pulse is in Square distribution, thus the refractive index of the fiber core is $n_{0}+n_{2} I_{i n}$.
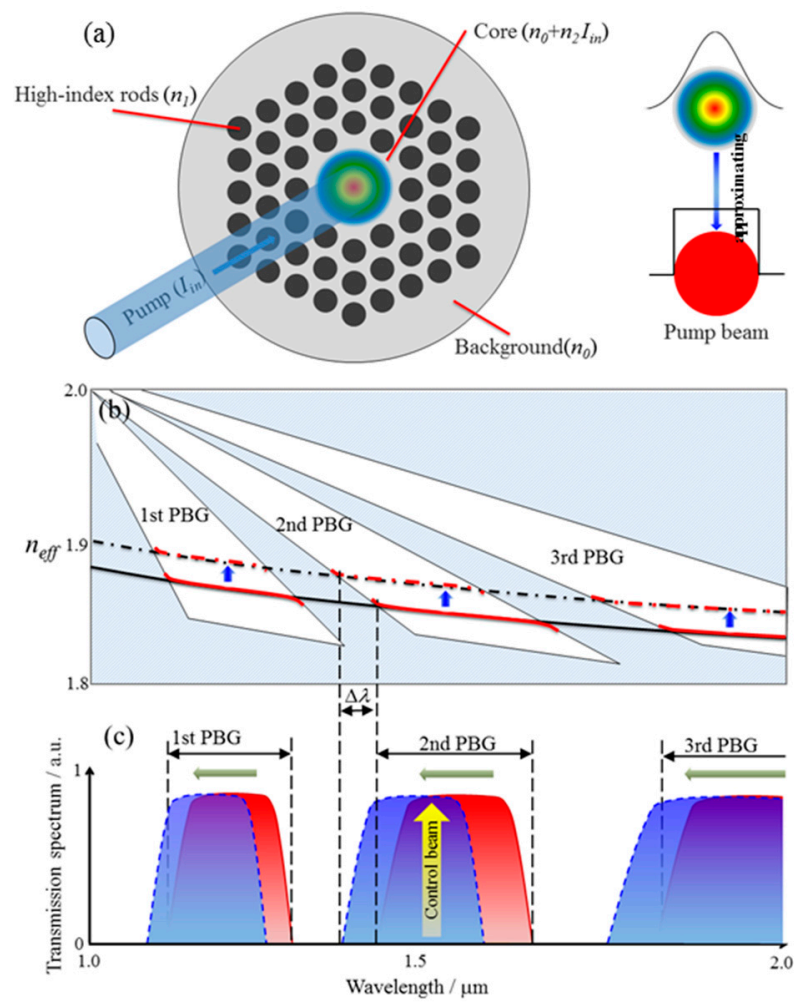

Figure 1. (a) Control beam with intensity $I_{\text {in }}$ transmitting in the core of an all-solid PBGF. (b) BPG regions appear from $1.0 \mu \mathrm{m}$ to $2.0 \mu \mathrm{m}$. (c) Schematic diagram of the transmission shift induced by OKE in an all-solid tellurite PBGF.

For an all-solid PBGF fabricated using the traditional fiber material (silica), the nonlinear refractive index coefficient $n_{2}$ is small. As a result, $n_{2} I_{\text {in }}$ is negligible in spite of the increase of the control pulse intensity. However, for an all-solid PBGF fabricated using tellurite glasses, $n_{2}$ is much larger, thus with the increase of $I_{i n}, n_{0}+n_{2} I_{\text {in }}$ will grow significantly, which will lead to changes in the transmission property. When $I_{\text {in }}$ reaches a certain value, $n_{0}+n_{2} I_{\text {in }}$ may even exceed the effective refractive index of the cladding, and at this point the light guiding mechanism in the fiber will shift from PBG to the total internal reflection. 
Figure $1 b, c$ is a principle schematic diagram of the all-optical signal modulation induced by OKE based on the PBG map of an all-solid tellurite PBGF whose parameters were selected appropriately. In Figure $1 \mathrm{~b}$ we can see several BPG regions appear from $1.0 \mu \mathrm{m}$ to $2.0 \mu \mathrm{m}$. When the control pulse with intensity $I_{\text {in }}$ transmits in the fiber core, the mode's effective refractive index $n_{\text {eff }}$ will increase due to OKE and the $n_{\text {eff }}$ line will move upward. Consequently, the transmission bands will blue-shift, which is shown in detail in Figure 1c. The wavelength shift of the high frequency edge is tagged as $\Delta \lambda$. If the fiber core transmits a signal whose wavelength locates in the transmission band before the blue-shift and falls outside after the blue-shift, this signal will be "switched on" or "switched off" by the control pulse. This is the all-optical signal modulation we attempt to demonstrate in this paper.

Generally speaking, with the same fiber parameters, the double-clad structure has stronger ability in light confinement than the single-clad structure. Therefore, the all-solid double-clad tellurite PBGF was designed and fabricated to carry out the relevant analysis and experiment. It was fabricated by the stack-and-draw technique based on $65 \mathrm{TeO}_{2}-8 \mathrm{Li}_{2} \mathrm{O}-17 \mathrm{WO}_{3}-3 \mathrm{MoO}_{3}-7 \mathrm{Nb}_{2} \mathrm{O}_{5}$ (TLWMN, high-index rods), $70 \mathrm{TeO}_{2}-15 \mathrm{ZnO}-5 \mathrm{Na}_{2} \mathrm{O}-10 \mathrm{La}_{2} \mathrm{O}_{3}$ (TZNL, background) and $17 \mathrm{TeO}_{2}-16 \mathrm{ZnO}-15 \mathrm{Li}_{2} \mathrm{O}-10 \mathrm{~K}_{2} \mathrm{O}-2 \mathrm{Al}_{2} \mathrm{O}_{3}-40 \mathrm{P}_{2} \mathrm{O}_{5}$ (TZLKAP, cladding) glasses $[27,28]$. Table 1 shows the linear reflective indices $\left(n_{0}\right)$ and softening temperatures of the three glasses $\left(T_{0}\right)$, which were measured by the prisms method and a thermal expansion analyzer (TMA8310), respectively. The softening temperatures were similar but the linear reflective indices were different. The transmission spectrum was measured as shown in Figure 2. All three glasses exhibited excellent transmission property in the mid-infrared region.

Table 1. Reflective indices and softening temperatures of TLWMN, TZNL, and TZLKAP glasses.

\begin{tabular}{cccc}
\hline Parameters & Materials & Reflective Index $@ \mathbf{~ 1 5 5 0 ~} \mathbf{~ m m}$ & Softening Temperatures $/{ }^{\circ} \mathbf{C}$ \\
\hline High-index rod & TLWMN & 2.058 & 371 \\
Inner cladding & TZNL & 1.963 & 359 \\
Outer cladding & TZLKAP & 1.601 & 366 \\
\hline
\end{tabular}

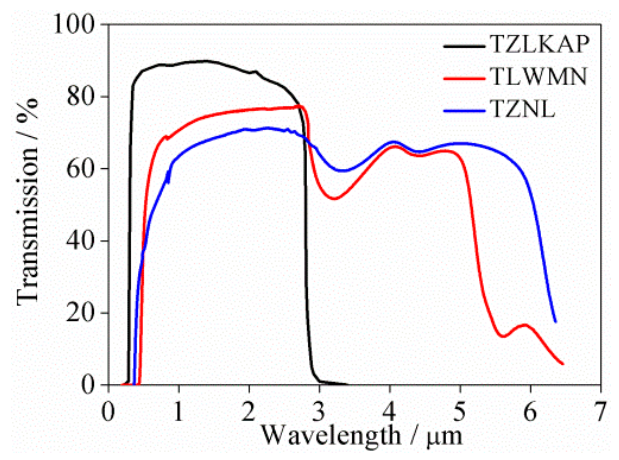

Figure 2. Spectra of TLWMN, TZNL, and TZLKAP glasses.

The fabrication process is specified in Figure 3. One TLWMN and one TZNL rod with a diameter of $12 \mathrm{~mm}$ were prepared by the casting method. One TZNL and one TZLKAP tube with a diameter of $12 \mathrm{~mm}$ were prepared by the rotational casting method. Step 1, the TLWMN and TZNL rods were respectively elongated to get a TLWMN capillary with a diameter of $\sim 7.2 \mathrm{~mm}$ and a TZNL capillary with a diameter of $\sim 1.0 \mathrm{~mm}$. Step 2, the TLWMN capillary was inserted into the TZNL tube and together elongated to produce a capillary with a diameter of $\sim 1 \mathrm{~mm}$. The cross section of the produced capillary was shown in the inset of Figure 3b. Step 3, the capillary obtained in Step 2 was cut into pieces of $20 \mathrm{~cm}, 36$ of which were stacked into the TZLKAP tube with the arrangement of three rings around a central TZNL capillary to produce the preform. Finally, the preform was drawn into the all-solid double-clad tellurite PBGF with $d=\sim 5.4 \mu \mathrm{m}$ and $\Lambda=\sim 9.0 \mu \mathrm{m}$. The insets of Figure $3 \mathrm{c}$ are photos of the preform (the upper one) and the successfully fabricated fiber (the lower one). During the fabrication process, a negative pressure of nitrogen gas was used to avoid the interstitial hole formation in the 
core-cladding interface. The PBG map of the all-solid double-clad tellurite PBGF with $d=\sim 5.4 \mu \mathrm{m}$ and $\Lambda=\sim 9.0 \mu \mathrm{m}$ was calculated by the commercial software based on the plane wave expansion method (PWM) which was formed by the mode coupling of the isolated high-index rod. The BPG map of the designed all-solid double-clad tellurite PBGF is shown in Figure 4.
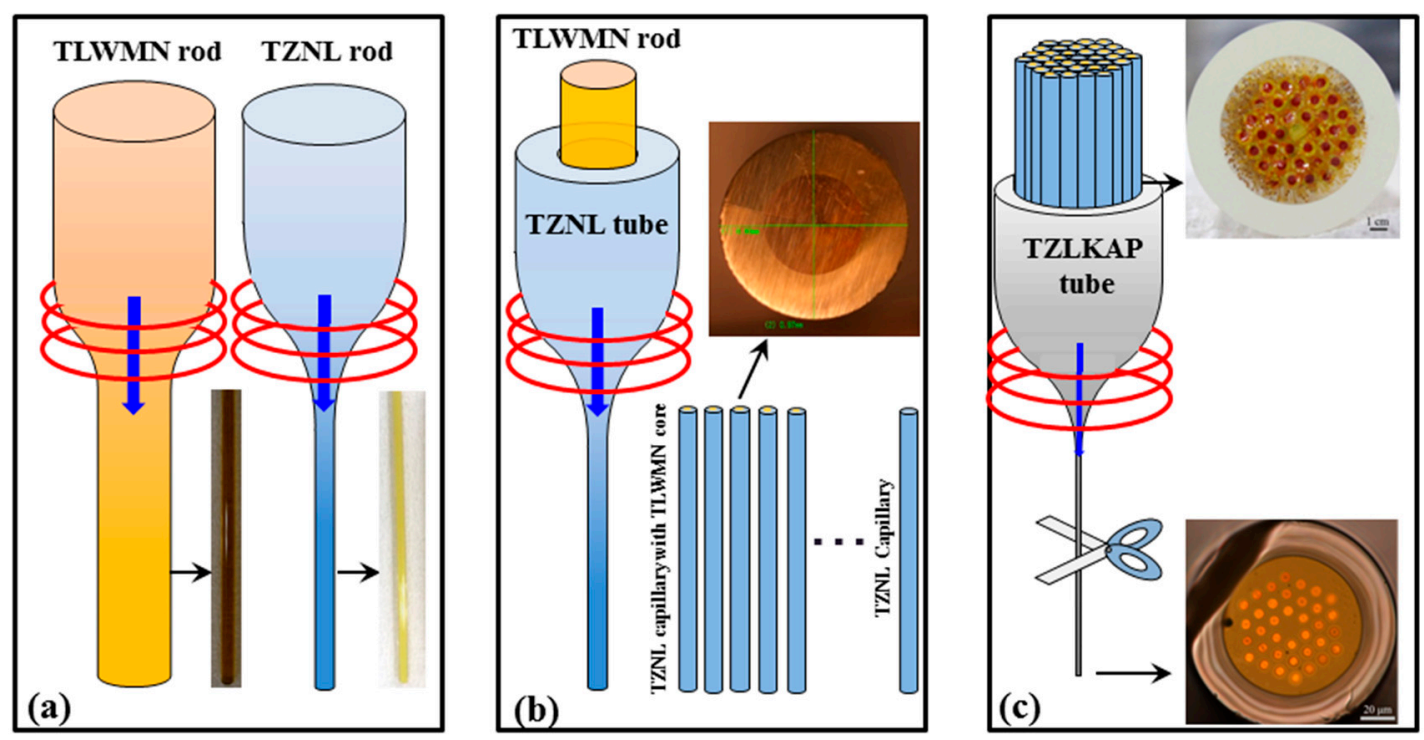

Figure 3. Fabrication process of the all-solid double-clad tellurite PBGF. (a) TLWMN and TZNL capillary. (b) Capillary with TLWMN core. (c) Fabricated the optical fibers.

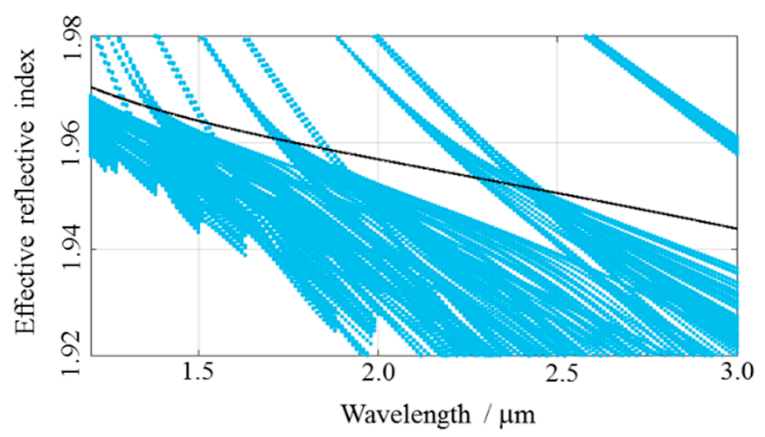

Figure 4. PBG map of the all-solid double-clad tellurite PBGF at $d / \Lambda=0.6$.

\section{Experiments and Results Discussion}

To investigate the ultrafast all-optical signal modulation in the all-solid double-clad tellurite PBGF, we focused on PBG located at 1540-1810 $\mathrm{nm}$ because most of the commercial laser sources were limited in the visible and near-infrared region. Moreover, to obtain the optimized power of the control pulse, the transmission spectrum was numerically simulated with the control pulse power increasing from 0 to $300 \mathrm{~kW}$, as shown in Figure 5. The yellow region was the transmission band, and the blue region was the transmission forbidden band. In the region of $1.50 \mu \mathrm{m}$ to $1.60 \mu \mathrm{m}$, the narrow transmission forbidden band shifted to the short wavelength with the increase of the power. Based on this simulation and our current experimental condition, a signal of $1.57 \mu \mathrm{m}$ and a control pulse of $200 \mathrm{~kW}$ and $200 \mathrm{fs}$ with the center wavelength of $1700 \mathrm{~nm}$ were selected for investigating the ultrafast all-optical signal modulation. 


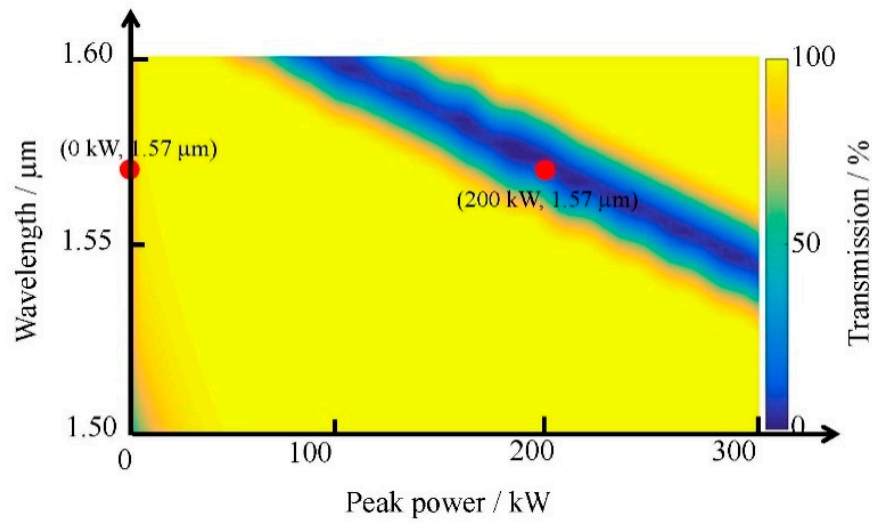

Figure 5. Calculated transmission spectrum of the all-solid double-clad tellurite PBGF with the control pulse power increasing from 0 to $300 \mathrm{~kW}$.

The signal in the all-solid double-clad tellurite PBGF can be all-optically controlled by the ultrafast single pulse with high power. Figure 6 shows the schematic diagram, in which the signal's output intensity is considered as 1 when it transmits normally in the core. When the ultrafast single pulse (200 fs) with the peak power of $200 \mathrm{~kW}$ is inputted into the fiber, OKE occurs and the signal falls into the transmission forbidden band. Consequently, no detection will be found from the fiber end: the signal is "switched off" by the ultrafast single pulse.

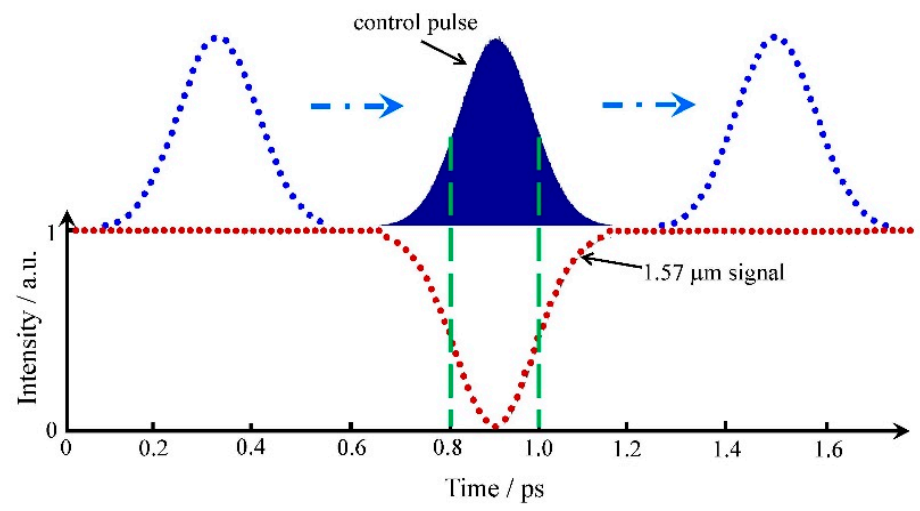

Figure 6. Schematic diagram of the all-optical signal modulation controlled by the ultrafast single pulse.

The experiment for investigating the ultrafast all-optical signal modulation was carried out in the $10 \mathrm{~cm}$ all-solid double-clad tellurite PBGF, as shown in Figure 7a. A tunable continuous-wave laser (Agilent, Santa Clara, CA, USA, 81600B-200) with a center wavelength of $1.57 \mu \mathrm{m}$ was used as the signal source, and a high power Erbium-doped fiber amplifier (EDFA, FITEL, ErFA11501, Japan) further boosted the signal to $200 \mathrm{~mW}$. A SMF was connected to a fiber collimation (FC) with a focus length of $11.29 \mathrm{~mm}$ and a numerical aperture (NA) of 0.24 (Thorlabs, Newton, NJ, USA, F220FC-1550). The control beam is the pulse with a duration of $200 \mathrm{fs}$ (full-width at half-maximum, FWHM), and a variable optical attenuator (VOA) was used to control its intensity. A beam splitter (BS, Thorlabs, BSW23) divided the signal into two beams, one of which was coupled into the fiber core by a $\mathrm{CaF}_{2}$ lens (Edmund Optics, Barrington, NJ, USA, DCX 25.4 X) together with the control pulse reflected by BS. The output pulse from TF was collected by a SMF and a tunable bandpass filter (BPF, Koshin Kogaku, Kanagawa, Japan, TFM-1550-S-SS) was used to separate the modulated signal from the control pulse. The signal was detected by an optical signal analyzer (OSA, Agilent Technologies, DCA-X 86,100 D, response time $10 \mathrm{ps}$ ) which can record the ultrafast signal. The center wavelength of the control pulse 
should locate inside the PBG region. The ultrafast single pulse has a high intensity of $200 \mathrm{~kW}$ and a duration of $200 \mathrm{fs}$.

(a)

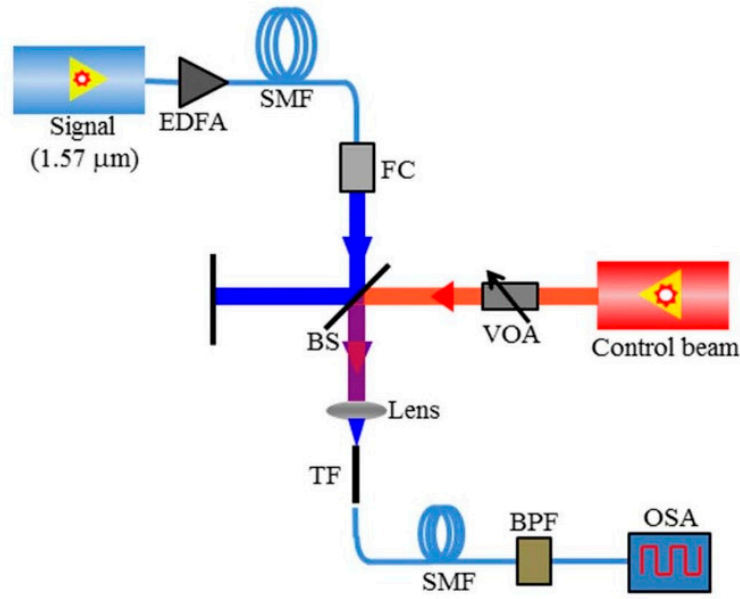

(b)

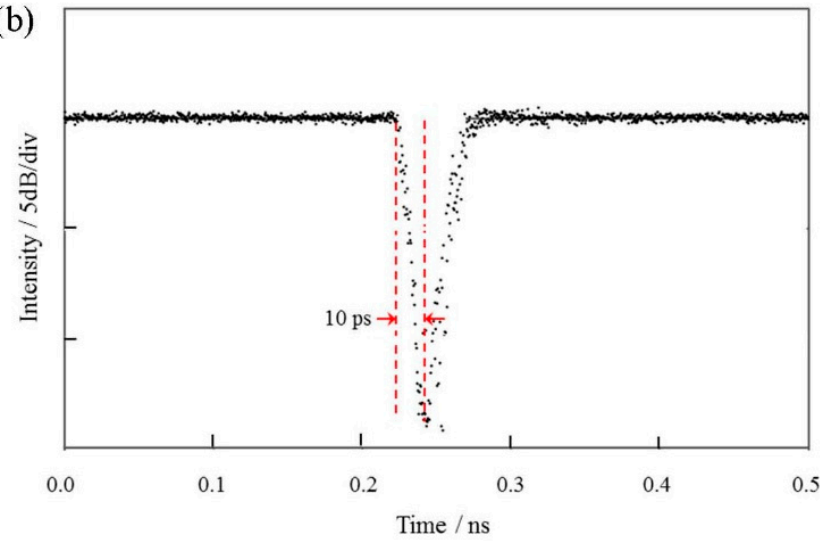

Figure 7. (a) Experimental setup for investigating the all-optical signal modulation controlled by the ultrafast single pulse in the all-solid double-clad tellurite PBGF. (b) Experimental results of the all-optical signal modulation controlled by the ultrafast single pulse.

Figure $7 \mathrm{~b}$ shows the experimental result of the all-optical signal modulation controlled by the ultrafast single pulse, where the horizontal and vertical coordinate represents time and output intensity, respectively. It is clear that when the ultrafast single pulse passed through the fiber core, there was a sudden slump in the output intensity detected by OSA, which corresponded with the theoretical analysis. In spite of the ultrafast single pulse being $200 \mathrm{fs}$, the signal's FWHM was detected to be $10 \mathrm{ps}$ due to the limit of OSA's response time. As a result, the modulation speed of this all-optical signal modulation switched by the ultrafast single pulse can reach $50 \mathrm{GHz}$, much faster than any commercial LN modulators.

\section{Conclusions}

In summary, to obtain significant OKE, an all-solid double-clad tellurite PBGF was designed and fabricated. A signal of $1.57 \mu \mathrm{m}$ and a control beam of $200 \mathrm{~kW}$ were used to investigate the ultrafast all-optical signal modulation in a $10 \mathrm{~cm}$ all-solid double-clad tellurite PBGF. When the ultrafast single pulse passed through the fiber core, OKE induced an obvious shift in the transmission bands, removing the signal outside the PBG region. The modulation speed can reach $50 \mathrm{GHz}$, faster than some commercial $\mathrm{LiNbO}_{3}$ modulators, which can be applied to multi-monitors, local area network, detectors, multi-sources, etc. 
Author Contributions: Conceptualization, T.C. and Y.O.; Methodology, T.C.; Software, S.T. and X.Z.; Validation, S.L. and X.Y.; Formal analysis, F.Z.; Data curation, T.S.; Writing-Original draft preparation, T.C.; Writing-Review and editing, F.Z. and X.Z.

Funding: This work is supported by National Natural Science Foundation of China $(61475134,61775032$, and 11604042), Fundamental Research Funds for the Central Universities (N170405007, N180406002, N180408018 and N160404009), JSPS KAKENHI Grant (15H02250, 17K18891 and 18H01504), JSPS and CERN under the JSPS-CERN joint research program, and 111 Project (B16009).

Acknowledgments: The authors thank the national "Young 1000 Talent Plan" program of China.

Conflicts of Interest: The authors declare no conflict of interest.

\section{References}

1. Kerr, J. LIV. A new relation between electricity and light: Dielectrified media birefringent (second paper). Lond. Edinb Dublin Philos. Mag. J. Sci. 1875, 50, 446-458. [CrossRef]

2. Maker, P.D.; Terhune, R.W.; Savage, C.M. Intensity-dependent changes in the refractive index of liquids. Phys. Rev. Lett. 1964, 12, 507. [CrossRef]

3. Stolen, R.H.; Ashkin, A. Optical Kerr effect in glass waveguide. Appl. Phys. Lett. 1973, 22, 294-296. [CrossRef]

4. Juvé, V.; Vaudel, G.; Ollmann, Z.; Hebling, J.; Temnov, V.; Gusev, V.; Pezeril, T. Ultrafast tunable modulation of light polarization at terahertz frequencies. Opt. Lett. 2018, 43, 5905-5908. [CrossRef] [PubMed]

5. Subkhangulov, R.R.; Mikhaylovskiy, R.V.; Zvezdin, A.K.; Kruglyak, V.V.; Rasing, T.H.; Kimel, A.V. Terahertz modulation of the Faraday rotation by laser pulses via the optical Kerr effect. Nat. Photonics 2016, 10, 111-114. [CrossRef]

6. Okamoto, K.; Marcatili, E.A.J. Chromatic dispersion characteristics of fibers with optical Kerr-effect nonlinearity. J. Lightware Technol. 1989, 7, 1988-1994. [CrossRef]

7. Liu, L.; Tian, Q.J.; Liao, M.S.; Zhao, D.; Qin, G.S.; Ohishi, Y.; Qin, W.P. All-optical control of group velocity dispersion in tellurite photonic crystal fibers. Opt. Lett. 2012, 37, 5124-5126. [CrossRef]

8. Mikhaylovskiy, R.V.; Subkhangulov, R.R.; Rasing, T.; Kimel, A.V. Colossal magneto-optical modulation at terahertz frequencies by counterpropagating femtosecond laser pulses in $\mathrm{Tb}_{3} \mathrm{Ga}_{5} \mathrm{O}_{12}$. Opt. Lett. 2016, 41, 5071-5073. [CrossRef]

9. Agrawal, G.P. Nonlinear fiber optics. In Nonlinear Fiber Optics, 5th ed.; Elsevier: San Francisco, CA, USA, 2013; pp. 195-211.

10. Domachuk, P.; Wolchover, N.A.; Cronin-Golomb, M.; Wang, A.; George, A.K.; Cordeiro, C.M.B.; Knight, J.C.; Omenetto, F.G. Over $4000 \mathrm{~nm}$ bandwidth of mid-IR supercontinuum generation in sub-centimeter segments of highly nonlinear tellurite PCFs. Opt. Express 2008, 16, 7161-7168. [CrossRef]

11. Shen, S.X.; Jha, A.; Huang, L.; Joshi, P. 980-nm diode-pumped $\mathrm{Tm}^{3+} / \mathrm{Yb}^{3+}$-codoped tellurite fiber for S-band amplification. Opt. Lett. 2005, 30, 1437-1439. [CrossRef]

12. Mori, A. Tellurite-based fibers and their applications to optical communication networks. J. Ceram. Soc. Jpn. 2008, 116, 1040-1051. [CrossRef]

13. Kumar, V.V.R.K.; George, A.K.; Knight, J.C.; Russell, P.S. Tellurite photonic crystal fiber. Opt. Express 2003, 11, 2641-2645. [CrossRef] [PubMed]

14. Gao, W.Q.; Cheng, T.L.; Deng, D.H.; Xue, X.J.; Suzuki, T.; Ohishi, Y. Third-harmonic generation with a more than $500 \mathrm{~nm}$ tunable spectral range in a step-index tellurite fiber. Laser Phys. Lett. 2014, 11, 095106. [CrossRef]

15. Ohishi, Y.; Mori, A.; Yamada, M.; Ono, H.; Nishida, Y.; Oikawa, K. Gain characteristics of tellurite-based erbium-doped fiber amplifiers for 1.5- $\mu \mathrm{m}$ broadband amplification. Opt. Lett. 1998, 23, 274-276. [CrossRef]

16. Wang, J.S.; Vogel, E.M.; Snitzer, E. Tellurite glass: A new candidate for fiber devices. Opt. Mater. 1994, 3, 187-203. [CrossRef]

17. Schmidt, M.A.; Granzow, N.; Da, N.; Peng, M.; Wondraczek, L.; RussellP., S.T.J. All-solid bandgap guiding in tellurite-filled silica photonic crystal fibers. Opt. Lett. 2009, 34, 1946-1948. [CrossRef]

18. Cheng, T.L.; Xue, X.J.; Gao, W.Q.; Suzuki, T.; Ohishi, Y. The Second-Order Raman Stokes Stronger Than the First-Order Raman Stokes Due to Inverse Raman Scattering in a Single Mode Tellurite Fiber. IEEE J. Quantum Electron. 2017, 53, 1-4. [CrossRef]

19. Lin, A.; Zhang, A.; Bushong, E.J.; Toulouse, J. Solid-core tellurite glass fiber for infrared and nonlinear applications. Opt. Express 2009, 17, 16716-16721. [CrossRef] 
20. Luan, F.; George, A.K.; Hedley, T.D.; Pearce, G.J.; Bird, D.M.; Knight, J.C.; Russell, P.S.J. All-solid photonic bandgap fiber. Opt. Lett. 2004, 29, 2369-2371. [CrossRef]

21. Bouwmans, G.; Bigot, L.; Quiquempois, Y.; Lopez, F.; Provino, L.; Douay, M. Fabrication and characterization of an all-solid 2D photonic bandgap fiber with a low-loss region $(<20 \mathrm{~dB} / \mathrm{km})$ around $1550 \mathrm{~nm}$. Opt. Express 2005, 13, 8452-8459. [CrossRef]

22. Li, J.; Fan, P.C.; Sun, L.P.; Wu, C.; Guan, B.O. Few-period helically twisted all-solid photonic bandgap fibers. Opt. Lett. 2018, 43, 655-658. [CrossRef] [PubMed]

23. Hu, X.W.; Shen, X.; Wu, J.J.; Peng, J.G.; Yang, L.Y.; Li, J.Y.; Li, H.Q.; Dai, N.L. All fiber M-Z interferometer for high temperature sensing based on a hetero-structured cladding solid-core photonic bandgap fiber. Opt. Express 2016, 24, 21693-21699. [CrossRef] [PubMed]

24. Kong, F.T.; Gu, G.C.; Hawkins, T.W.; Jones, M.; Parsons, J.; Kalichevsky-Dong, M.T.; Palese, S.P.; Cheung, E.; Dong, L. Efficient $240 \mathrm{~W}$ single-mode 1018nm laser from an Ytterbium-doped 50/400 $\mu \mathrm{m}$ all-solid photonic bandgap fiber. Opt. Express 2018, 26, 3138-3144. [CrossRef] [PubMed]

25. Li, G.R.; Zeisberger, M.; Schmidt, M.A. Guiding light in a water core all-solid cladding photonic band gap fiber-An innovative platform for fiber-based optofluidics. Opt. Express 2017, 25, 22467-22479. [CrossRef]

26. Knight, J.C. Photonic crystal fibres. Nature 2003, 424, 847. [CrossRef]

27. Cheng, T.L.; Sakai, Y.; Suzuki, T.; Ohishi, Y. Fabrication and characterization of an all-solid tellurite-phosphate photonic bandgap fiber. Opt. Lett. 2015, 40, 2088-2090. [CrossRef]

28. Cheng, T.L.; Tanaka, S.; Tuan, T.H.; Suzuki, T.; Ohishi, Y. All-optical dynamic photonic bandgap control in an all-solid double-clad tellurite photonic bandgap fiber. Opt. Lett. 2017, 42, 2354-2357. [CrossRef]

(C) 2019 by the authors. Licensee MDPI, Basel, Switzerland. This article is an open access article distributed under the terms and conditions of the Creative Commons Attribution (CC BY) license (http://creativecommons.org/licenses/by/4.0/). 